\title{
Natale Prägung
}

Bernhard Gurtner

Korrespondenz:

Dr. med. Bernhard Gurtner

Eggstrasse 76

CH-8620 Wetzikon

gurtner.bernhard@bluewin.ch
Robert Musil (1880-1942) erwähnte in seinen «Unfreundlichen Betrachtungen» einen berühmten Architekten, der herausgefunden hat, dass der Mensch, da er in der Klinik geboren wird und im Spital stirbt, auch seine Lebensräume mit aseptischer Nüchternheit ausfüllen müsse.

Wer dieser berühmte Architekt war, verschweigt uns der Dichter. Doch findet sich eine ähnliche Erkennt-
Da haben wir es! Die moderne Geburtshilfe hat nicht nur die Säuglingssterblichkeit gesenkt, sondern zugleich bei allen Neugeborenen ein lebenslang anhaltendes Bedürfnis erzeugt, ärztlich und medikamentös verwöhnt zu werden. Die Klinik als erster Sinneseindruck hinterlasse unauslöschbare Charakterprägungen. So wie es Konrad Lorenz (1903-1989) gelang, Graugänse unmittelbar nach dem Schlüpfen

\section{Jede Spitalgeburt erzeugt eine unlösbare Bindung an die Mediziner, die künftig für jegliche Beschwerden beigezogen werden.}

nis auch in der Weihnachtsgeschichte «Un bébé sur la paille» des französischen Schriftstellers Michel Tournier (*1924): Ein Neugeborenes, das auf einem Operationstisch zur Welt kommt, als erstes den Geruch von Desinfektionsmitteln einatmet, elektrische Apparate summen hört und vor den lackierten Wänden des Gebärsaales nur Gespenster in weissen Mänteln und mit aseptischen Gesichtsmasken um sich sieht - ich behaupte, dass dieses Kind kraft einer solchen Natalprägung stets eine Neigung zur Klinikomanie, zur Medikomanie und zur Pharmakomanie haben wird.

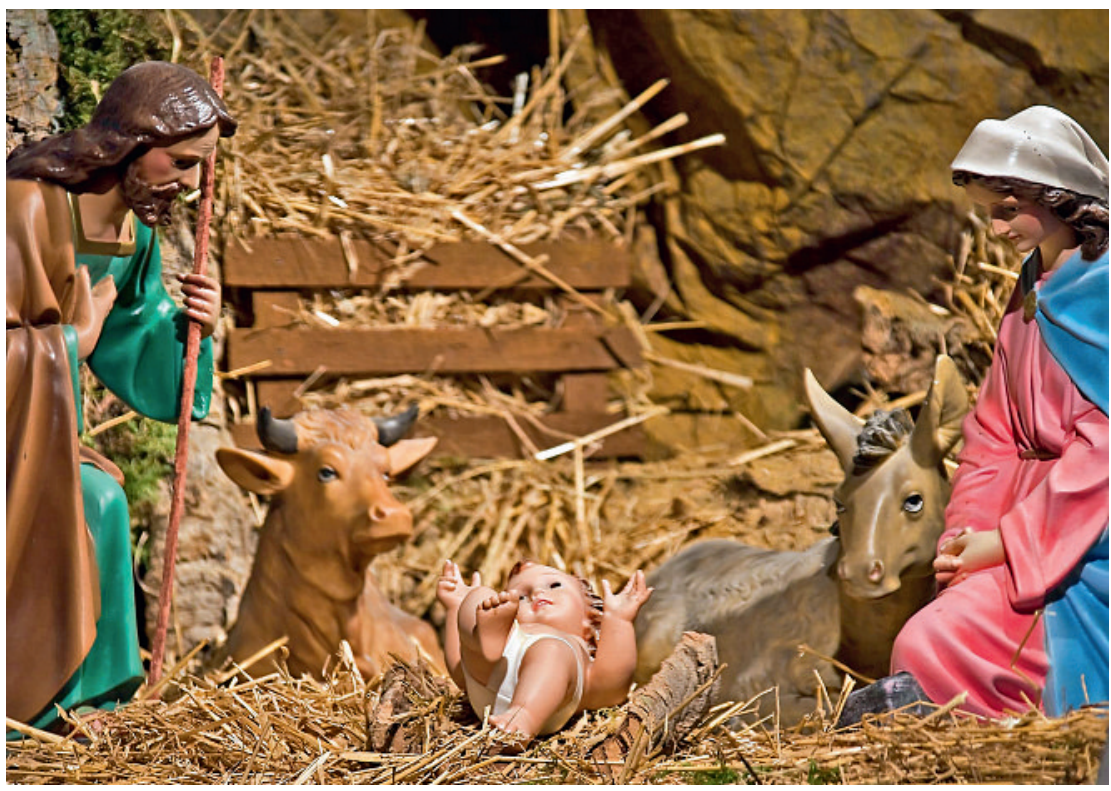

auf sich selbst als Ersatzmutter zu fixieren, so erzeuge jede Spitalgeburt eine unlösbare Bindung an die Mediziner, die inskünftig für jegliche Beschwerden beigezogen werden.

Normale Geburten dürften daher nach dem listigen Vorschlag von Tournier nicht mehr in hochtechnisierten Kliniken erfolgen, sondern hätten an einem Ort zu geschehen, dessen eindrückliche Schönheit die Kinder davor bewahre, sich schon am ersten Tag ihres Lebens als Kranke zu fühlen. Tiere, die in freier Natur geworfen werden, seien kräftiger als ihre Artgenossen, die im geheizten Stall bei Kunstlicht mit tierärztlicher Hilfe entbunden werden. Warum sollte das nicht auch für menschlichen Nachwuchs gelten?

Eine naturnahe und stressfreie Methode hat bekanntlich Frédérick Leboyer $\left({ }^{\star} 1918\right)$ nach seinen Erfahrungen in Indien als «Sanfte Geburt» in der westlichen Welt erfolgreich propagiert. Seither hat sich vieles im Umgang mit Neugeborenen und ihren Müttern zum Guten gewendet, der apparative Aufwand ist aber noch grösser geworden. Könnte dieser allererste Eindruck einer technisierten Umgebung den kleinen Erdenbürger nachhaltig beeinflussen?

Welche segensreichen Nachwirkungen die von Strohrascheln und animalischen Gerüchen begleitete Geburt im Stall von Bethlehem gebracht hat, wird uns in den nächsten Tagen erinnerlich gemacht. Doch kein Verfechter der natalen Prägung möchte daraus folgern, dass statt Arzt und Hebamme besser Ochs und Eselin an die Säuglingsbetten zu stellen wären, um das kranke Gesundheitswesen auf wundersame Art zu heilen. 